\title{
Economic evaluation of solar hybrid electric systems for rural electrification
}

\author{
Paul C. Okonkwo ${ }^{1}$, Srinivasan Murrgan ${ }^{l}$, El Manaa Barhoumi ${ }^{2}$, Fadhil Khadoum Al Housni $^{l}$, Tofayel Ahmed ${ }^{l}$, Nabil \\ Abdul Rahim Al-Alawi ${ }^{l,}$ Ebele Anastesia Okonkwo ${ }^{l}$, Nnamdi Michael Azubuike ${ }^{3}$ \\ ${ }^{1}$ Mechanical \& Mechatronics Engineering Department, College of Engineering, Dhofar University, Salalah, Oman \\ ${ }^{2}$ Electrical Engineering Department, College of Engineering, Dhofar University, Salalah, Oman \\ ${ }^{3}$ Civil Engineering Department, School of Engineering and Engineering Technology, FUTO, Owerri, Nigeria
}

\begin{abstract}
Diesel generators have long been in use in rural communities despite, the impact of emission caused by these generators to the environment. Due to the need for a greener environment, such electric generating systems seem not to be environmentally friendly and need to be addressed.Connection to the grid can also be expensive. This paper investigates the feasibility of employing hybrid electric system in rural communities. The HOMER software that analyzes system configuration was used to study the application and functional limitation of each hybridised arrangement. The result showed that the solar renewable energy (RE) based system has lower cost of capital cost, replacement cost and O\&M cost with higher energy production compared to grid connected system, making the solar RE system most economically viable and a better candidate for the rural community electrification demands.
\end{abstract}

\section{Introduction}

Fossil fuels have been used for power generation in different parts of the world since the arrival of industrial revolution in the mid 1700 s to 1800 s when coal replaced biomass. The supply of fossil fuel is likely to be limited in the coming years due to government policies, production and logistic challenges. Furthermore, continuous increase in the global energy demand has resulted in electric generation through various sources [1]. Most of the electric generation sources have focused on reneweable energy that addresses the International and national challenge of golbal warming due to their sustainability, clean and ecofriendly in nature [2]. Renewable energy has the potential of reducing global warming and providing low carbon environment [3].

Solar energy has recently become one of the renewable energy sources and its performance depends on several environmental factors of which photovoltaic (PV) module plays an impotant role [2]. PV module is used in hybrid energy system (HES) and can be arranged as standalone or grid connected systems [3]. Study and modeling of solar radiation requires the knowledge of prevailing meteorological variables. Amongst the meteorological variables is the thermal radiation which is vital when considering PV energy power generation. Combination of multiple energy sources can not only provide stable and reliable energy supply but can also reduce the emission from some of the energy sources, making such a system more efficient and effective. Hybrid arrangement of RE sources has been a common method for electrical energy production [4]. Mehrpoova et al. [5] investigated the economic and environmental impacts of using HES for rural electrification. The result showed evidence of optimal application of the HES to rural communty electrification. However, the sensitivy analysis of some key indicators were not investigated. In another study, comparison of two HESs of renewable and non-RE systems for a household application was perfomed by $\mathrm{Li}$ et al. [6]. The non-RE was found to be more viable than the RE system. Lorafe et al. [7] performed a detailed comparative study of off-grid island communities using HOMER software. Two scenarios of HES and PV stand-alone systems were considered. The result showed that HES is more feasible and effective than the stand-alone solar system. Nandi et al. [8] investigated the option of employing HES and stand-alone generator for rural electrification in Bangladish. Hybrid configuration is influenced by site location and resource availability. Hence, transportation of fuel can be an important issue of concern for remote areas. Hybridization of renewable energy sources with combustible based energy sources can enhance the availability of the electrical supply as well as support the battery band of the RE source that often needs regular maintenance. Researchers have shown that hybird systems are not only cost effective but have lower cost of energy (COE), compared to single system in meeting desired electrical demands [4]. Incooporating selected components in the hybrid system can imporve the relaibility of the HES. However, the electrical energy challenges of a particular city can be different from another and requires a particular approach. The present

Corresponding author: pokonkwo@du.edu.om 
study examines the availability of RE sources in unelectrified area of Salalah region.

\subsection{Location of the study}

Salalah is situated in the southern part of Oman, approximately $1000 \mathrm{~km}$ away from the capital city of Muscat. Salalah is the second biggest city in Oman and lies between $40^{\circ} 14^{\prime} \mathrm{N}$ to $40^{\circ} 05^{\prime} \mathrm{N}$ latitudes and $25^{\circ} 39^{\prime} \mathrm{E}$ to $26^{\circ} 00^{\prime} \mathrm{E}$ longitudes on the map.

\subsection{Hybrid system configuration}

Hybridization is the process of combining different energy sources to improve the system's dependability and overall system efficiency. The diesel generator added to the system is used to supplement electrical energy source when the renewable energy or nonrenewable energy sources are not able to meet the electrical load demand as well act as a standalone system. Inclusion of diesel generator in the hybrid configuration also ensures that power is automatically supplied directly to either the load. Battery is connected to the electric system is to accumulate and store energy from the system and power during the day and deliver the stored energy to the system when electrical load is demanded, and the renewable energy sources are not available to supply energy. Fig. 1 shows the combination of two hybridized energy systems employed in this study.
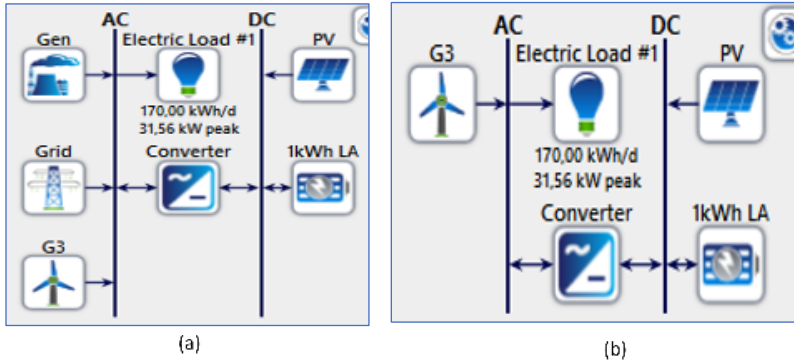

Fig. 1. Schematic diagram of the hybridized (a) PV/Genset/Wind/Battery/Grid and (b) PV/Wind/Battery systems.

\subsection{Load profiles analysis}

Understanding the community and the load requirement is important in addressing the load demand. Electrical source development and optimal sizing of the system components are necessary in load modeling and analysis. HOMER software calculates the operating hours of the electrical appliances using probabilistic approach [4]. While probabilistic approach can be used to calculate the costs of energy, the technical drawback of reducing the cost of distributed networks can be challenging.

\subsection{Solar energy availability and radiation}

In a hybridized PV system arrangement, sunlight strikes the PV module and electricity is generated through electrolysis process. Direct current (DC) produced through this process needs to be converted to alternating current (AC) to power the electrical load $[5,6]$. HOMER software calculates the PV array in terms of rated KW and assumes the output of the PV array to be related to the incident radiation [7]. Based on the co-ordinate's requirement in HOMER, $40^{\circ} 11^{\prime} \mathrm{N}$ latitude and $25^{\circ} 54^{\prime} \mathrm{E}$ longitude which is the Centrum of Salalah was used in the analysis. The information from the latitude and longitude positions of a plane is used by HOMER software to acquire the clearness index. Knowledge of clearness index is required to access the potential of sunlight in a given region. Annual solar radiation cycle varies from season to season and the change in the season is influenced by several factors such as rain, fog, wind, temperature, sunlight [8]. HOMER calculates solar radiation values for $8760 \mathrm{~h}$ of the year [9]. The algorithm is easy to use because it needs only the latitude and the monthly averages to execute the calculation [9]. Fig. 2 shows the average solar radiation for one year and the corresponding clearness index.

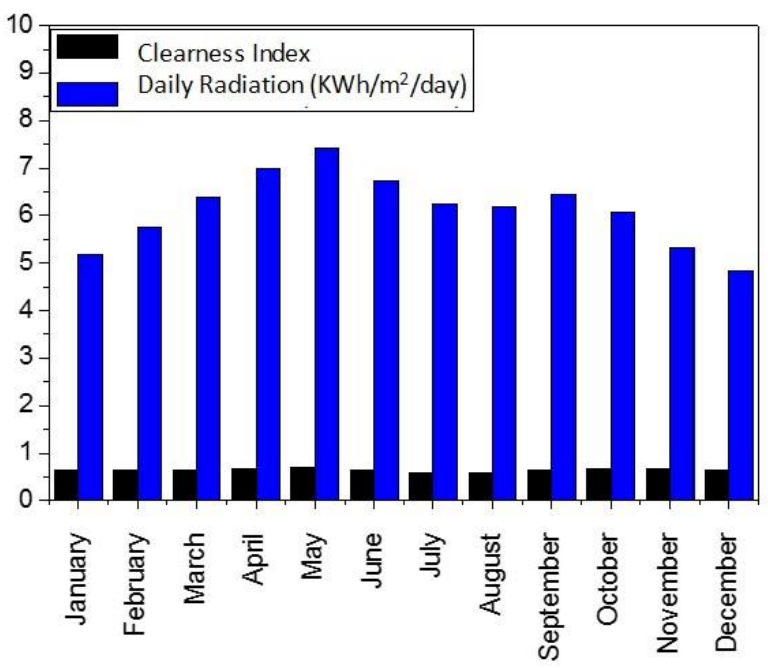

Fig. 2. Average solar radiation data for Salalah.

The clearness index shown in the Fig. 2 describes the availability of solar radiation and variation in the atmospheric weather in Salalah. Fig 2. Shows that the solar radiation starts increasing from January and reach the peak in May. It declines from June until September, before it increased with subsequent decline in the solar radiation from October to the end of the year. It is evident from Fig. 2 that July and August have relatively low solar irradiation. Abdul-Wahab et al. [10] reported that the Salalah region surface sea temperature during this period is colder than the air passing over the surface and few degrees below dew-point.

\section{Modeling and simulation}

HOMER software developed by Natural Renewable Energy Laboratory (NREL) was used in this technoeconomic study. HOMER requires meteorological data of the components for the stimulation and optimization analysis [11]. The system components and their designs, including the off-grid and grid-connected components are incorporated in the HOMER analysis. For typical 
hybridized electrical power source arrangement, two or more energy conversion or storage devices is necessary [12]. By combining different generating sources, the disadvantages of each one can be minimized. The component costs, technology options and availability are used by the HOMER software in modeling different system layouts and predicting the entire system total cost as well as system life time [13].

\section{Result and discussion}

\subsection{Optimization and cost assessment results}

The average monthly electrical production throughout the year for the two HESs is shown in Fig. 3.

\section{Monthly Average Electric Production}
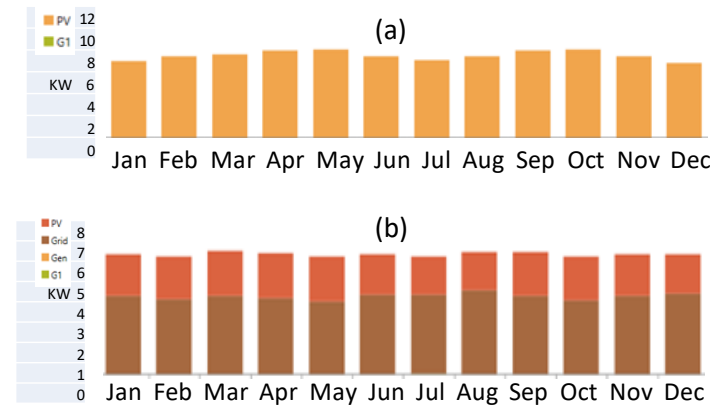

Fig.3. Monthly average electric production from (a) $\mathrm{PV} / \mathrm{Genset} / \mathrm{W}$ ind and (b) PV/Genset/Wind/Grid systems

According to Fig 3a, significant amount of the total energy of $96.8 \%(62,050 \mathrm{KWh} / \mathrm{yr})$ is produced by the PV system. The remaining part of the energy generated is supplied by either the Genset or turbine source in the percentages of 1.8 and $1.4 \%$ respectively.

HOMER software performs optimization layout of the hybridized system by employing the combination of various variables such as electrical load, energy cost, and size of each component as well as economic parameters in the simulation. The total electric generation, consumption and excess electricity produced by the two hybrid systems is shown in Fig. 4.

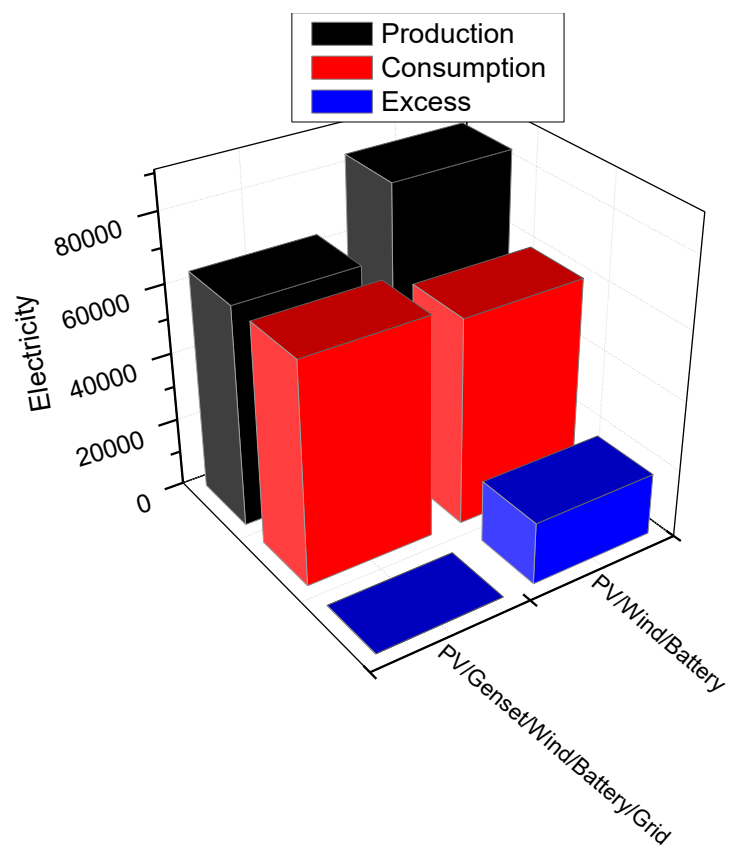

Fig. 4. Electric production, usage and excess for the two hybrid system.

It can also be seen that the electricity production from the PV/Wind/Battery system is higher than that of PV/Genset/Wind/Battery/Grid system. Similarly, the energy consumptions of both systems are closely related due to similar load demand. However, the little difference observed in the electric consumption can be ascribed to the usage of electricity by some of the system components that have higher capital price [14]. Higher excess energy is seen for the PV/Wind/Battery system due to higher energy produced in this system compared to the PV/Genset/Wind/Battery/Grid system, making the PV/Wind/Battery hybrid energy system the preferred choice for power arrangement for Salalah community.

It has been shown that optimal planning and assessment of suitability of a given system can be based on the replacement, annual, operation and maintenance (O\&M) costs [15]. The comparative cost analysis of the system components in terms of the capital cost, replacement cost and O\&M cost are shown in Fig. 5.

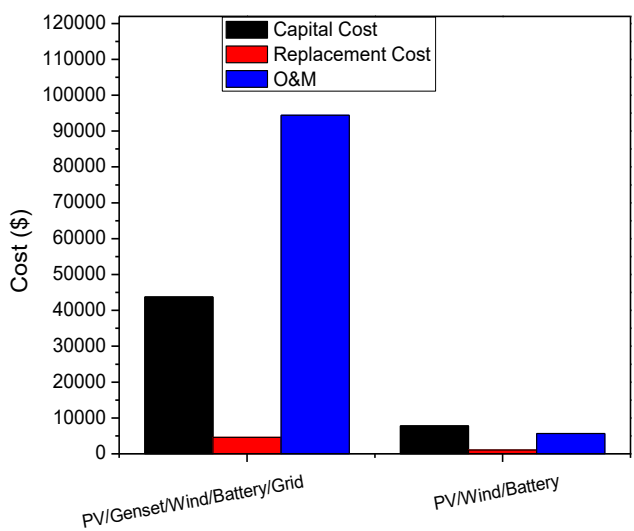

Fig. 5. System cost comparison 
The overall costs for the PV/Genset/wind/Battery/Grid system is higher than that of the PV/wind/Battery system and can be attributed to higher number of components required for the grid-connected system. Higher capital cost can also be ascribed to the high cost of electrolizer, PV system and other components incorporated into the PV/Genset/wind/Battery/Grid system. The results make the PV/wind/Battery renewable energy system considered in this study more economically viable for the community electrification than the other system counterpart.

\section{Conclusion}

Cost effective modeling software was used to study the feasibility of two different hybridized energy systems that meet the high electrical energy demand of the Salalah Community. Pure renewable and grid connected systems were modeled to supply power to the required load in the region. Hybridized renewable energy system was found to fulfill the electric demand compared to the grid connected system. The two systems were also analyzed and compared in terms of the capital cost, replacement cost, operating cost and their potentials in meeting the Salalah community-based load. The PV/Wind/Battery system has lower O\&M and replacement costs compared to grid connected system making the renewable hybrid system the preferred energy source for the Salalah electrification. The outcome of this study would be helpful to the policy maker in Salalah region in implementing renewable energy hybrid system to the Salalah community than connecting to the grid that may be challenging.

\section{Reference}

1. G. De Vita, K. Endresen, L.C. Hunt, An empirical analysis of energy demand in Namibia, Energy policy, 34(18), 3447-3463 (2006)

2. H. Lund, Renewable energy strategies for sustainable development, Energy, 32(6), 912-919 (2007)

3. S. Bilgen, S. Keleş, A. Kaygusuz, A. Sarı, K. Kaygusuz, Global warming and renewable energy sources for sustainable development: a case study in Turkey, Renewable and sustainable energy reviews, 12(2), 372-396 (2008)

4. H. Energy, Homer pro version 3.7 user manual, HOMER Energy: Boulder, CO, USA, (2016)

5. P. Mesarić, S. Krajcar, Home demand side management integrated with electric vehicles and renewable energy sources, Energy and Buildings, 108, 1-9 (2015)

6. J. Aghaei, M.-I. Alizadeh, Demand response in smart electricity grids equipped with renewable energy sources: A review, Renewable and Sustainable Energy Reviews, 18, 64-72 (2013)

7. H.-R. Seo, G.-H. Kim, S.-Y. Kim, N. Kim, H.-G. Lee, C. Hwang, M. Park, I.-K. Yu, Power quality control strategy for grid-connected renewable energy sources using PV array and supercapacitor, 2010 International Conference on Electrical Machines and Systems, 2010, IEEE, pp 437-441

8. A.R. Stine, P. Huybers, I.Y. Fung, Changes in the phase of the annual cycle of surface temperature, Nature, 457(7228), 435 (2009)

9. B.U. Kansara, B. Parekh, Modelling and simulation of distributed generation system using HOMER software, 2011 International Conference on Recent Advancements in Electrical, Electronics and Control Engineering, 2011, IEEE, pp 328-332

10. S.A. Abdul - Wahab, Analysis of thermal inversions in the Khareef Salalah region in the Sultanate of Oman, Journal of Geophysical Research: Atmospheres, 108(D9), (2003)

11. O. Mestre, P. Domonkos, F. Picard, I. Auer, S. Robin, E. Lebarbier, R. Böhm, E. Aguilar, J.A. Guijarro, G. Vertacnik, HOMER: a homogenization softwaremethods and applications, (2013)

12. C. Wang, H. Nehrir, F. Lin, J. Zhao, From hybrid energy systems to microgrids: Hybridization techniques, configuration, and control, IEEE PES General Meeting, 2010, IEEE, pp 1-4

13. A. Shiroudi, R. Rashidi, G. Gharehpetian, S. Mousavifar, A. Akbari Foroud, Case study: Simulation and optimization of photovoltaic-windbattery hybrid energy system in Taleghan-Iran using homer software, Journal of Renewable and Sustainable Energy, 4(5), 053111 (2012)

14. S. Ashok, Optimised model for community-based hybrid energy system, Renewable energy, 32(7), 1155-1164 (2007)

15. M. Haratian, P. Tabibi, M. Sadeghi, B. Vaseghi, A. Poustdouz, A renewable energy solution for standalone power generation: A case study of KhshU SiteIran, Renewable Energy, 125, 926-935 (2018) 